\title{
Expression of Ski in the Granulosa Cells of Atretic Follicles in the Rat Ovary
}

\author{
Hyun KIM ${ }^{1)}$, Keitaro YAMANOUCHI ${ }^{1)}$ and Masugi NISHIHARA ${ }^{1)}$ \\ ${ }^{1)}$ Department of Veterinary Physiology, Veterinary Medical Science, The University of Tokyo, \\ Tokyo 113-8657, Japan
}

\begin{abstract}
The aim of the present study was to locate Ski protein, a product of cellular protooncogene $c$-ski, in rat ovaries in order to predict the possible involvement of Ski in follicular development and atresia. First, expression of $c$-ski mRNA in the ovaries of adult female rats was confirmed by RT-PCR. Then, ovaries obtained on the day of estrus were subjected to immunohistochemical analysis for Ski and proliferating cell nuclear antigen (PCNA) in combination with terminal deoxynucleotidyl transferase-mediated dUTP nick end-labeling (TUNEL). Ski was expressed in granulosa cells that were positive for TUNEL, but negative for PCNA, regardless of the size of follicles. Expression of Ski in TUNEL-positive granulosa cells, but not in PCNA-positive granulosa cells, was also verified in immature hypophysectomized rats having a single generation of developing and atretic follicles by treatment with equine chorionic gonadotropin. These results indicate that Ski is profoundly expressed in the granulosa cells of atretic follicles, but not in growing follicles, and suggests that Ski plays a role in apoptosis of granulosa cells during follicular atresia.
\end{abstract}

Key words: Apoptosis, Follicular atresia, Granulosa cell, Ovary, Ski

(J. Reprod. Dev. 52: 715-721, 2006)

C ellular protooncogene $c$-ski was originally shown to induce myogenesis when transfected to non-myogenic quail embryo cells in vitro [1]. Transgenic mice expressing the c-ski gene under the control of a murine sarcoma virus long terminal repeat show large increases in their skeletal muscle mass [2], while c-ski-deficient mice have defects in their skeletal muscle development [3]. In addition, mice lacking $c$-ski show perinatal lethality due to defects in neurulation and craniofacial patterning as well as skeletal muscle development, and excessive apoptosis has been detected in $c$-skideficient mouse embryos $[4,5]$, supporting the idea that Ski can act as an anti-apoptotic factor [6]. It has also been suggested that $c$-ski is involved in

Accepted for publication: July 7, 2006

Published online: August 23, 2006

Correspondence: M. Nishihara (e-mail: amnishi@mail.ecc.utokyo.ac.jp) mediating the proliferative effect of $17 \beta$-estradiol in uterine epithelial cells [7]. Thus, c-ski gene product (Ski) has been implicated as having dual roles in both regulating proliferation and differentiation of cells. However, little is known about the pathways through which Ski exerts its actions.

Among the tissues in which c-ski expression has been identified [8], the role of $c$-ski in ovarian tissue remains unknown. However, the expression of $c-$ ski gene does not necessarily indicate the presence of Ski protein, since degradation of Ski protein has been implicated as one of the regulatory mechanisms of Ski function [9]. The rat has an incomplete $4-5$ day estrous cycle, and their ovaries contain follicles at various stages of development (growing follicles, preovulatory follicles, and atretic follicles) during the estrous cycle. The rat ovary may, therefore, be useful for prediction of the role of Ski protein by immunohistochemical 
analyses. In addition, several experimental models that represent specific stages of follicular development have been established in the rat [10, 11]. The aim of the present study was, by means of immunohistochemical techniques, to locate the Ski protein in rat ovaries during the estrous cycle and in ovaries with a having single generation of developing and atretic follicles in order to predict the possible involvement of Ski in follicular development and atresia.

\section{Materials and Methods}

\section{Animals}

Mature male and female Wistar-Imamichi rats were purchased from the Imamichi Institute of Animal Reproduction (Ibaraki, Japan). Rats were housed under controlled light conditions (12 h light; lights on 07:00-19:00), and food and water were given ad libitum. All animals received humane care according to the Guide for the Care and Use of Animals of The University of Tokyo. Vaginal cytological examinations were carried out daily, and only those animals showing consecutive regular 4-day estrous cycles were used. Ovaries were obtained from 8- to 14-week-old rats at estrus. Rats were sacrificed by cervical dislocation, and their ovaries were collected and quickly frozen in liquid nitrogen for RT-PCR or embedded in OCT compound (Sakura Finetechnical, Tokyo, Japan) for immunohistochemical detection of $\mathrm{Ski}$, proliferating cell nuclear antigen (PCNA), and terminal deoxynucleotidyl transferase (TdT)mediated dUTP nick end-labeling (TUNEL), respectively. The obtained samples were stored at $-80 \mathrm{C}$ until use.

Immature female Wistar-Imamichi hypophysectomized rats (at the age of 25 days) were purchased and housed as described above. They were treated subcutaneously with equine chorionic gonadotropin (eCG; 15 IU in $200 \mu 1$ saline) at the age of 26 days for induction of ovarian follicular development and subsequent atresia due to the lack of hypophyseal LH surge. The rats were sacrificed by cervical dislocation at 0,2 , and 4 days after treatment and their ovaries were excised. After removal of connective tissues, the ovaries were embedded and stored as described above. Blood samples were also collected, and after the sera were separated by centrifugation, they were stored at $-20 \mathrm{C}$ until assayed for estradiol concentration. Serum concentrations of estradiol were measured by $17 \beta$-estradiol enzymeimmunoassay kits (Cayman Chemical, Ann Arbor, MI, USA) according to the manufacturer's protocol.

Reverse transcription-polymerase chain reaction (RTPCR)

Total RNA was isolated from the cerebrum, cerebellum, small intestine, lung, heart, skeletal muscle, spleen, kidney, liver, uterus, ovary, fat, prostate gland, and testis of adult rats. One hundred $\mathrm{mg}$ of the tissue was homogenized in $1 \mathrm{ml}$ of TRIzol reagent (Invitrogen, Carlsbad, CA, USA) with a Digital Homogenizer (Iuchi, Osaka, Japan). After adding $200 \mu \mathrm{l}$ of chloroform, the mixture was centrifuged at 15,000 rpm for $15 \mathrm{~min}$ at $4 \mathrm{C}$. An equal volume of 2-propanol was added to the supernatants, which was then centrifuged at 15,000 rpm for $15 \mathrm{~min}$ at $4 \mathrm{C}$. The RNA pellet was rinsed with $70 \%$ ethanol, dried, and dissolved in $30 \mu \mathrm{l}$ diethylpyrocarbonate-treated water. First-strand cDNA was synthesized using SuperScript II (Invitrogen) with oligo $\mathrm{d}(\mathrm{T}) 16$ primers (500 $\mu \mathrm{g} / 2.5$ $\mu \mathrm{M})$ as described in the manufacturer's instruction. The primer set used for amplification of the partial rat $c$-ski cDNA fragment consisted of the forward primer 5'-ACC ATC TCG TGC TTC GTG GTG GGA-3' and reverse primer 5'-CTC CTT GCC CGT GTA ATC CTG GCT-3' and was designed on the basis of the DNA sequences of the mouse and human $c$-ski genes published in the literature [1214]. Rat-specific glyceraldehyde-3-phosphate dehydrogenase (GAPDH) primers were designed using the Primer3 software (available at http:/ / fokker.wi.mit.edu/primer3/) and the forward primer was 5'-CAT TGT TGC CAT CAA CGA CCC CTT-3' and the reverse primer was 5'-ACT CAG CAC CAG CAT CAC CCC ATT-3'. PCR was carried out using $\alpha$ Taq polymerase (Bionex, Seoul, Korea) according to the manufacturer's recommended protocol. The $c-s k i$ genes were amplified under following conditions: 1 cycle of 94 $\mathrm{C}$ for $5 \mathrm{~min}$; 30 cycles of $94 \mathrm{C}$ for $1 \mathrm{~min}, 55 \mathrm{C}$ for 1 $\mathrm{min}$, and $72 \mathrm{C}$ for $1 \mathrm{~min}$; and 1 cycle of $72 \mathrm{C}$ for 10 min. The GAPDH genes were amplified under following conditions: 1 cycle of $94 \mathrm{C}$ for $5 \mathrm{~min}$; 35 cycles of $94 \mathrm{C}$ for $1 \mathrm{~min}, 60 \mathrm{C}$ for $1 \mathrm{~min}, 72 \mathrm{C}$ for 1 min; and 1 cycle of $72 \mathrm{C}$ for $10 \mathrm{~min}$. The predicted PCR amplified sizes of $c$-ski and GAPDH were 561 and $194 \mathrm{bp}$, respectively. After PCR, an aliquot of 
the reaction mixture was electrophoresed on $1 \%$ agarose gel and the products were visualized with ethidium bromide staining.

\section{Immunohistochemical analysis of Ski and PCNA}

Frozen tissue sections ( $5 \mu \mathrm{m}$ thick) were prepared from the OCT-embdedded rat ovary tissues and subjected to immunohistochemical analysis for detection of Ski and PCNA. The sections were airdried and fixed in $4 \%$ paraformaldehyde (PFA) in phosphate-buffered saline (PBS) for $30 \mathrm{~min}$, followed by incubation in $0.1 \%$ Triton X-100 in PBS for 15 min. After washing with PBS, endogenous peroxidase activity was inactivated by incubation in $0.3 \%$ hydrogen peroxide in methanol for $30 \mathrm{~min}$. Then, the sections were immersed in blocking solution [ $8 \%$ skim milk plus 5\% normal goat serum (NGS) in PBS] for $30 \mathrm{~min}$. The primary rabbit antibody specific for Ski (Santa Cruz Biotechnology, Santa Cruz, CA, USA; diluted to $1: 100$ with $5 \%$ NGS in PBS) or mouse monoclonal antibody specific for PCNA (Santa Cruz Biotechnology; diluted to 1:200 with 5\% NGS in PBS) was applied and the sections were incubated for $90 \mathrm{~min}$. After washing in PBS, the sections were incubated with the MAX-PO simple stain ( $R$, for rabbit primary antibody; Nichirei, Tokyo, Japan) or MAX-PO (M, for mouse primary antibody; Nichirei), which was a horseradish peroxidase conjugated secondary antibody, for $60 \mathrm{~min}$, and then positive signals were developed with 3,3'diaminobenzidine (DAB; dojindo, Kumamoto, Japan). The sections were counterstained with hematoxylin to visualize nuclei.

\section{Determination of apoptotic cells by TUNEL}

Frozen sections from ovaries ( $5 \mu \mathrm{m}$ thick) were air-dried and fixed in $4 \%$ PFA in PBS for $30 \mathrm{~min}$. To detect DNA fragmentation, TUNEL was performed using a commercial kit (In Situ Cell Detection Kit, POD, Roche, Penzberg, Germany). All experiments were performed according to the manufacturer's instructions. The slides were rinsed with PBSblocking solution $\left(3 \% \mathrm{H}_{2} \mathrm{O}_{2}\right.$ in methanol) and incubated with permeabilization solution $(0.1 \%$ Triton $\mathrm{X}-100$ in $0.1 \%$ sodium citrate) for $2 \mathrm{~min}$ on ice. After several washes with PBS, the samples were incubated with TdT and detection buffer conjugated with horseradish peroxidase (Converter-POD) in a humid chamber for $60 \mathrm{~min}$ at 37 C. Positive signals were developed with DAB, and the sections were counterstained with hematoxylin to visualize nuclei.

For double-staining of Ski and TUNEL, the sections were first similarly prepared for immunohistochemistry for Ski, and then they were incubated with Alexa Fluor 488 conjugated goat anti-rabbit IgG $(\mathrm{H}+\mathrm{L})$ (Invitrogen) for $60 \mathrm{~min}$. Then, the slides were incubated with permeabilization solution for $2 \mathrm{~min}$. After washing with PBS, the slides were incubated with TdT and fluorescein-dUTP in a humid chamber for $60 \mathrm{~min}$ at 37 C. Signals were observed under a fluorescent microscope (BX50, Olympus, Tokyo, Japan) equipped with a digital camera (DP70, Olympus, Tokyo, Japan).

\section{Statistical analyses}

Statistical analyses were conducted using the StatView software (version J5, Abacus Concepts, Inc., Berkley, CA, USA). A one-way analysis of variance and Dunnett's test were used to determine differences in serum concentrations of estradiol between the eCG-treated and control groups. Differences were considered statistically significant at $\mathrm{P}<0.05$.

\section{Results}

\section{Expression of c-ski gene in the tissues}

To analyze the tissue distributions of the $c$-ski gene in the rat, RT-PCR analysis was performed. As shown in Fig. 1, the $c$-ski gene was expressed in all the tissues examined, which was in agreement with the previous findings made in mice by Lyons et al. [8] and in equine by Yamanouchi et al. [13]. The ovary was one of the tissues that intensively expressed the $c$-ski gene.

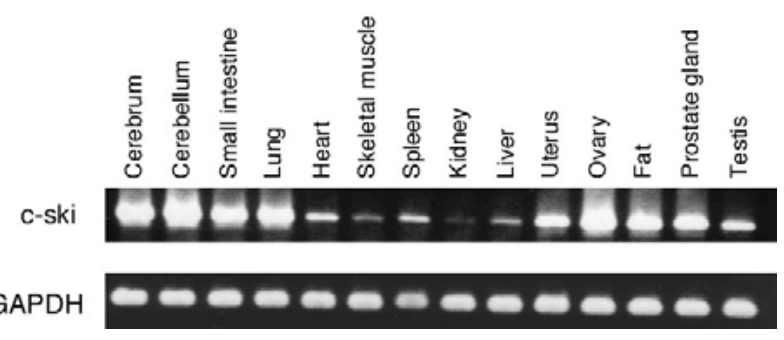

Fig. 1. RT-PCR analysis of the c-ski (upper) and GAPDH (lower) genes in various tissues from adult male and female rats. 


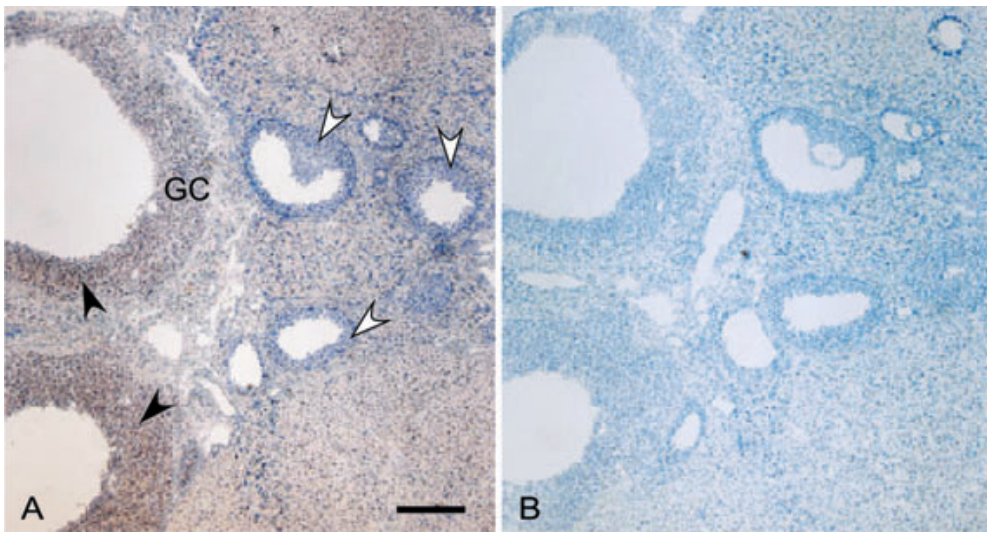

Fig. 2. Immunohistochemical analysis of Ski in the ovarian follicles of an adult female rat at estrus. A and B are adjacent sections showing Ski-staining and the negative control (without the primary antibody), respectively. Black and white arrowheads indicate Ski-positive and Ski-negative granulosa cells, respectively. GC, granulosa cells. Scale bar $=400 \mu \mathrm{m}$.
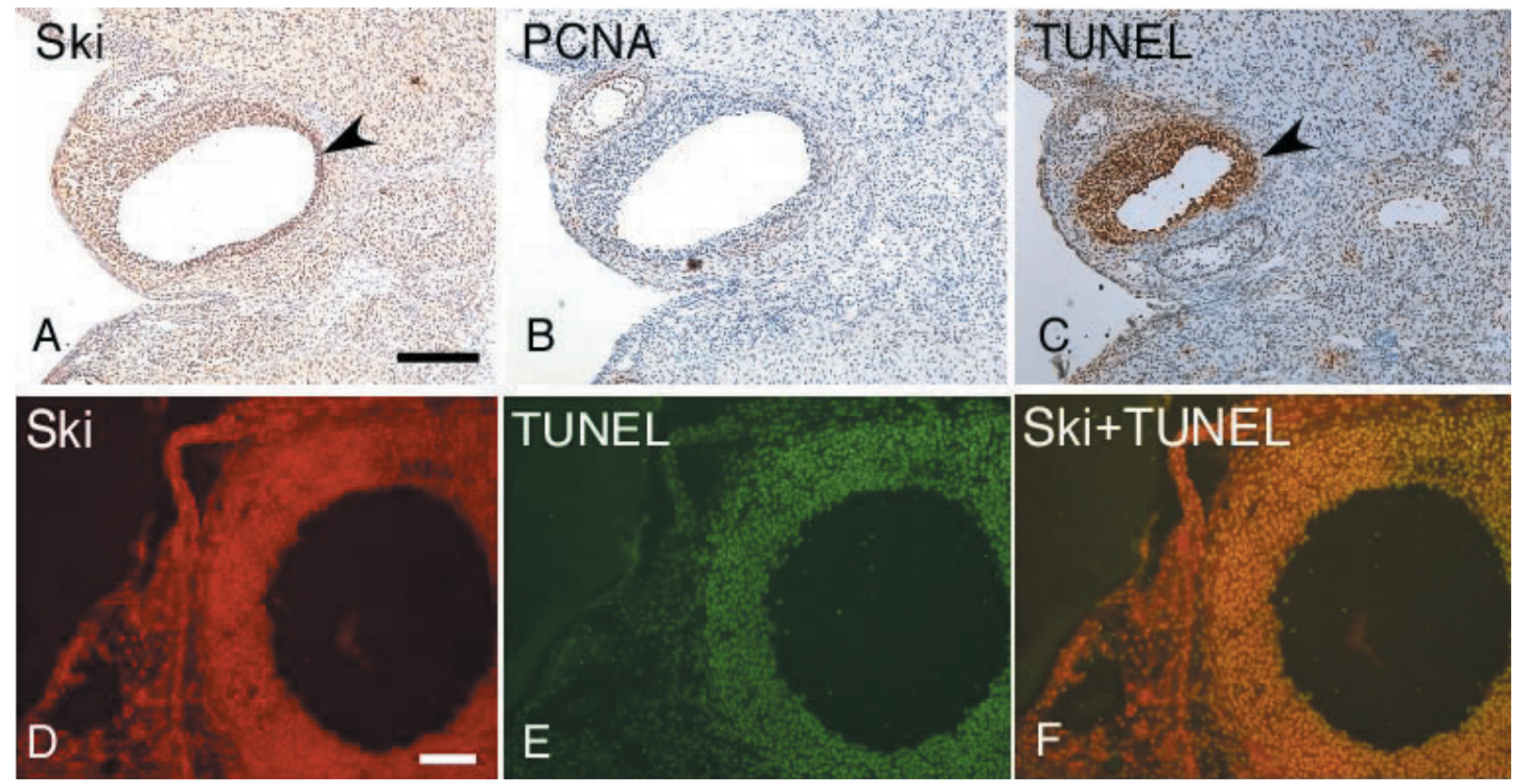

Fig. 3. Immunohistochemical analyses of Ski (A) and PCNA (B); TUNEL-staining (C); immunofluorescent double-staining of Ski (D) and TUNEL (E); and a merged image of D and E (F). These analyses were conducted on the follicles of adult rats. Note that the granulosa cells are positive for Ski and TUNEL (arrowheads in A and B, respectively), but negative for PCNA. Also note that the Ski-positive granulosa cells (red in D) and TUNEL-positive granulosa cells (green in E) mostly overlap (yellow in F). Scale bars $=400 \mu \mathrm{m}$ in A and $200 \mu \mathrm{m}$ in D.

Localization of Ski protein in the follicles of adult female rats

To locate Ski protein expression in the ovaries of adult females, immunohistochemical analysis was performed. As shown in Fig. 2, the granulosa cells of follicles exhibited both positive and negative staining for Ski regardless of the size of follicles. Since Ski has been implicated as playing roles in cell proliferation $[4,6,7]$ and has been predicted to act as an anti-apoptotic factor [5], the above results showing a distinct Ski protein expression pattern in granulosa cells led us to examine the relationship 
between follicular growth and/or atresia and Ski protein expression. For this purpose, serial ovarian sections of adult rats were subjected to immunohistochemical analyses of Ski and PCNA and to TUNEL. As shown in Fig. 3A-C, Skiimmunoreactive signals were observed in the granulosa cells of follicles where TUNEL-positive, but not PCNA-negative, granulosa cells were present. Further double-histochemical analysis revealed that the Ski-positive cells overlapped with TUNEL-positive cells (Fig. 3D-F).

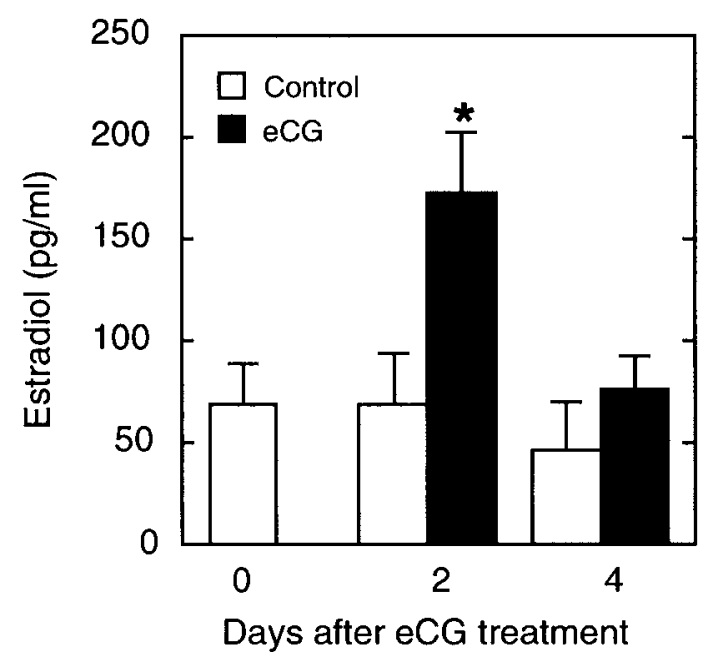

Fig. 4. Serum estradiol concentrations of eCGprimed immature hypophysectomized rats. Each column and vertical bar represents the mean \pm SE $(n=6)$. ${ }^{*}, P<0.05$.
Localization of Ski protein in the follicles of eCGprimed immature hypophysectomized rats

Serum estradiol concentrations were measured 0 , 2 , and 4 days after eCG administration to immature hypophysectomized rats. As shown in Fig. 4, serum estradiol concentrations were significantly higher in the eCG-primed rats than in the control rats 2 days after administration, indicating that eCG treatment successfully induced follicular growth. However, 4 days after treatment, there was no difference in the estradiol concentrations between the control and eCG-primed rats, indicating the occurrence of follicular atresia. Two days after eCG administration, more follicles with PCNA positive granulosa cells became evident, indicating an increased number of growing follicles, but no Ski-positive TUNEL-positive granulosa cells were observed in the antral follicles (Fig. 5A, B and C). Four days after eCG administration, however, a large number of follicles with TUNEL-positive granulosa cells appeared, indicating that these follicles were undergoing atresia, and the granulosa cells in these atretic follicles were positive for Ski protein and negative for PCNA (Fig. 5D, E and F).

\section{Discussion}

The present study demonstrated that $c$-ski mRNA is strongly expressed in rat ovaries and that a

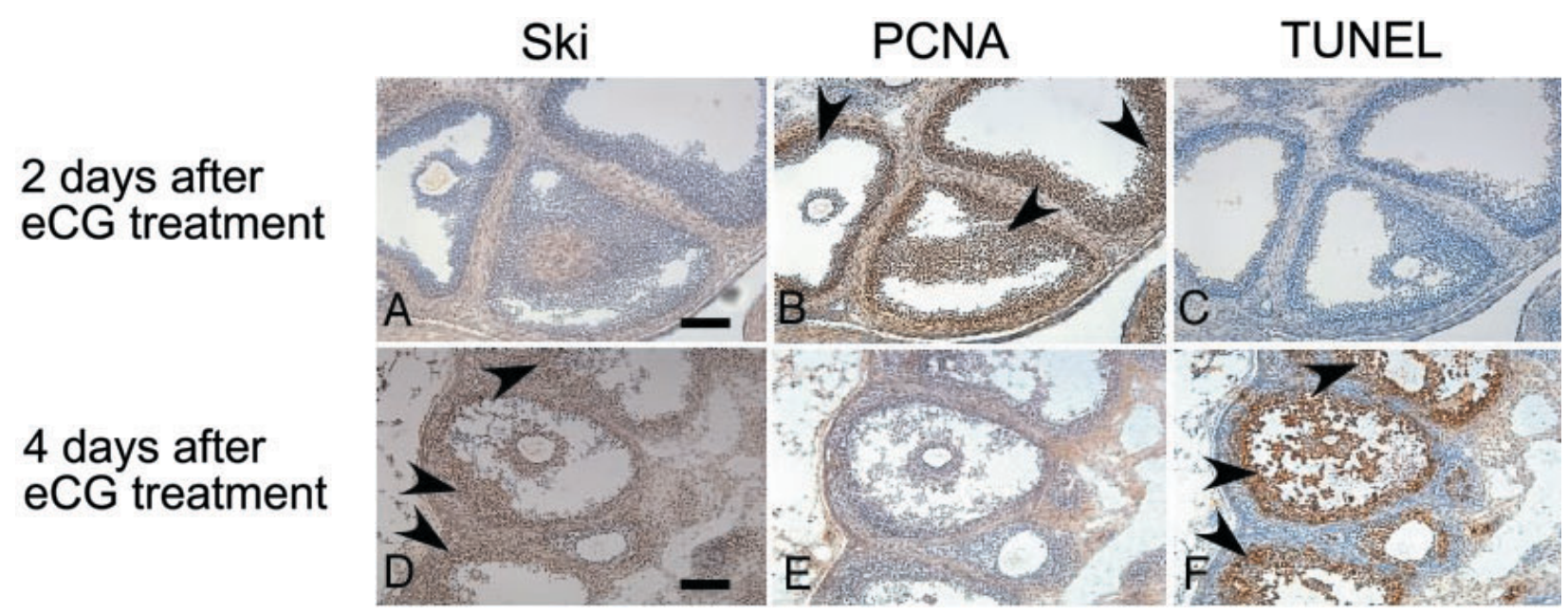

Fig. 5. Histochemical analyses of ovarian sections from eCG-primed immature hypophysectomized rats. A, B and C are adjacent sections showing the Ski, PCNA and TUNEL signals, respectively, 2 days after eCG treatment. D, E and F are adjacent sections showing Ski, PCNA and TUNEL signals, respectively, 4 days after eCG treatment. Arrowheads indicate positive signals for PCNA (B), Ski (D) and TUNEL (F) in granulosa cells. Scale bars $=400 \mu \mathrm{m}$. 
considerable number of follicles of different sizes express Ski protein. Further histochemical examination revealed that Ski was expressed in granulosa cells that were positive for TUNELstaining, but not for PCNA immunoreactivity, suggesting that Ski is expressed in cells undergoing apoptosis, but not in proliferating cells. Many researchers have investigated the molecular mechanisms of follicular selection, and apoptosis of granulosa cells is regarded as the first phenomenon in follicular atresia [15]. Taken together, Ski may be one of the key molecules involved in follicular atresia in rat ovaries.

Furthermore, to examine whether Ski is expressed in TUNEL-positive granulosa cells, but not in PCNA-positive granulosa cells, in the immature rat model, immunohistochmical and TUNEL analyses were also performed on ovaries having a single generation of follicles. Gonadotropin is an important survival factor for developing follicles in escaping atresia and reaching the preovulatory follicle stage [16-20]. Moreover, preovulatory follicles that are not exposed to an LH surge during the appropriate period undergo atresia [21-25]. Immature hypophysectomized rats primed with eCG are known to exhibit development of a single generation of follicles and subsequent follicular atresia due to lack of an LH surge [26]. In the present study, 2 days after eCG treatment when the serum estradiol levels were significantly elevated, the great majority of the follicles were positive for PCNA immunoreactivity although they did not express the Ski protein. Four days after eCG treatment, however, most of the follicles were positive for TUNEL-staining, and they also expressed Ski signals. These observations also support the involvement of Ski in follicular atresia.
Ski has been demonstrated in a variety of tissues $[8,13]$ as in the present study and is suggested to play multiple roles in a variety of cell types [27-29]. For example, Ski is expressed in proliferating myoblast [6] and uterine epithelial cells [7]. In the uterus, endometrial $c$-ski gene expression has been induced by estrogen treatment, which is known to induce proliferation of uterine epithelial cells [7], and progesterone treatment eliminated estrogeninduced $c$-ski expression [30]. In addition, $c$-ski is known to induce myogenic differentiation of quail embryonic cells [29]. Thus, most studies to date have indicated that Ski mediates cell proliferation and differentiation [31-33]. In relation to apoptosis, mice deficient for $c$-ski show excessive apoptosis [4, 5], suggesting that Ski also plays a role as an antiapoptotic factor. Thus, the present notion that Ski is involved in apoptosis proposes a new concept regarding the $S k i$ function. The mechanism underlying the Ski-induced apoptosis of granulosa cells, if present, is currently unknown. Ski, as a nuclear protein, has been shown to be associated with a variety of other cellular proteins [34, 35], and it is believed that a unique property of Ski enables it to express multiple functions [28-30]. In this regard, the search for novel Ski-interacting proteins in granulosa cells would be of interest in further clarifying the uncovered function of Ski.

In conclusion, although the exact roles of Ski and the regulatory mechanism of its expression are currently unknown, the present study demonstrated that high levels of Ski are expressed in atretic follicles, but not in healthy follicles. Ski may be involved in inducing apoptosis of granulosa cells and may play a key role in follicular selection. Further studies are needed to clarify its function, interaction, and correlation with other molecules in rat ovaries.

\section{References}

1. Colmenares C, Stavnezer E. The ski oncogene induces muscle differentiation in quail embryo cells. Cell 1989; 59: 293-303.

2. Sutrave P, Kelly AM, Hughes SH. Ski can cause selective growth of skeletal muscle in transgenic mice. Genes Dev 1990; 4: 1462-1472.

3. Berk M, Desai SY, Heyman HC, Colmenares C. Mice lacking the ski proto-oncogene have defects in neurulation, craniofacial, patterning, and skeletal muscle development Genes Dev 1997; 11: 2029-2039.
4. Shinagawa T, Nomura T, Colmenares C, Ohira M, Nakagawara A, Ishii S. Increased susceptibility to tumorigenesis of ski-deficient heterozygous mice. Oncogene 2001; 20: 8100-8108.

5. Berk M, Desai SY, Heyman HC, Colmenares C. Mice lacking the ski proto-oncogene have defects in neurulation, craniofacial patterning, and skeletal muscle development. Genes Dev 1997; 11: 2029-2039.

6. Soeta C, Suzuki M, Suzuki S, Naito K, Tachi C, Tojo $\mathbf{H}$. Possible role for the $c$-ski gene in the 
proliferation of myogenic cells in regenerating skeletal muscles of rats. Dev Growth Differ 2001; 43: 155-164.

7. Yamanouchi K, Soeta C, Harada R, Naito K, Tojo H. Endometrial expression of cellular protooncogene $c$-ski and its regulation by estradiol17beta. FEBS Lett 1999; 449: 273-276.

8. Lyons GE, Micales BK, Herr MJ, Horrigan SK, Namciu S, Shardy D, Stavnezer E. Protooncogene $c$-ski is expressed in both proliferating and postmitotic neuronal populations. Dev Dyn 1994; 201: 354-365.

9. Kokura K, Kaul SC, Wadhwa R, Nomura T, Khan MM, Shinagawa T, Yasukawa T, Colmenares C, Ishii $\mathrm{S}$. The Ski protein family is required for MeCP2-mediated transcriptional repression. J Biol Chem 2001; 276: 34115-34121.

10. Dhanasekaran N, Moudgal NR. Biochemical and histological validation of a model to study follicular atresia in rats. Endocrinol Exp 1989; 23: 155-166.

11. Shi F, LaPolt PS. Relationship between FoxO1 protein levels and follicular development, atresia, and luteinization in the rat ovary. J Endocrinol 2003; 179: 195-203.

12. Nomura N, Sasamoto S, Ishii S, Date T, Matsui M, Ishizaki R. Isolation of human cDNA clones of $s k i$ and the ski-related gene, sno. Nucleic Acids Res 1989; 17: 5489-5500.

13. Yamanouchi K, Kano K, Soeta C, Hasegawa T, Ishida N, Mukoyama H, Tojo H, Tachi C. Studies on expression of the $c$-ski gene in equine (Thoroughbred) tissues. J Equine Sci 1997; 8: 13-19.

14. Namciu S, Lyons GE, Micales BK, Heyman HC, Colmenares C, Stavnezer E. Enhanced expression of mouse $c$-ski accompanies terminal skeletal muscle differentiation in vivo and in vitro. Dev Dyn 1995; 204: 291-300.

15. Manabe N, Goto Y, Matsuda-minehata F, Inoue N, Maeda A, Sakamaki K, Miyano T. Regulation mechanism of selective atresia in porcine follicles: Regulation of granulosa cell apoptosis during atresia. J Reprod Dev 2004; 50: 493-514.

16. Byskov AG. Follicular atresia. In: Jones RE (ed.), The Vertebrate Ovary. Comparative Biology and Evolution. New York: Plenum; 1978: 533-562.

17. Greenwald GS, Terranova PF. Follicular selection and its control. In: Knobil E, Neill J (eds.), The Physiology of Reproduction. New York: Raven Press; 1988: 387-435.

18. Hirshfield AN. Development of follicles in the mammalian ovary. Int Rev Cytol 1991; 124: 43-101.

19. Hirshfield AN. Size-frequency analysis of atresia in cycling rats. Biol Reprod 1988; 38: 1181-1188.

20. Byskov AG. Atresia. In: Midgley FR, Sadler WA (eds.), Ovarian Follicular Development and Function. New York: Plenum Press; 1979: 41-58.

21. Hori T, Ide M, Miyake T. Pituitary regulation of preovulatory estrogen secretion in the rat. Endocrinol Japon 1969; 16: 351-360.

22. Mahesh VB. The dynamic interaction between steroids and gonadotropins in the mammalian ovulatory cycle. Neurosci Biobehav Rev 1985; 2: 245260.

23. Tebar M, Ruiz A, Gaytan F, Sanchez-Criado JE. Follicular and luteal progesterone play different roles synchronizing pituitary and ovarian events in the 4-day cyclic rat. Biol Reprod 1995; 53: 1183-1189.

24. Donath J, Nishino Y, Schulz T, Michna H. The antiovulatory potential of progesterone antagonists correlates with a down-regulation of progesterone receptors in the hypothalamus, pituitary and ovaries. Ann Anat 2000; 182: 143-150.

25. Asai S, Ohta R, Shirota M, Sato M, Watanabe G, Taya K. Reproductive endocrinology in Hatano high- and low-avoidance rats during the estrous cycle. Endocrine 2002; 18: 161-166.

26. Boone DL, Carnegie JA, Rippstein PU, Tsang BK. Induction of apoptosis in eCG-primed rat ovaries by anti-eCG antibody. Biol Reprod 1997; 57: 420-427.

27. Heyman HC, Berk M, Desai SY, Colmenares C. Mice lacking the ski proto-oncogene have defects in neurulation, craniofacial, patterning, and skeletal muscle development. Genes Dev 1997; 11: 2029-2039.

28. Ambrose MR, Bottazzi ME, Goodenow MM. Expression of the c-ski proto-oncogene during cell cycle arrest and myogenic differentiation. DNA Cell Biol 1995; 14: 701-707.

29. Colmenares C, Stavnezer E. The ski oncogene induces muscle differentiation in quail embryo cells. Cell 1989; 59: 293-303.

30. Yamanouchi K, Soeta C, Naito $K$, Tojo $H$. Progesterone pretreatment inhibits the expression of c-ski mRNA and epithelial cell proliferation induced by estrogen in the rat uterus. J Reprod Dev 2000; 46: 257-263.

31. Luo K. Negative regulation of BMP signaling by the ski oncoprotein. J Bone Joint Surg Am 2003; 3: 39-43.

32. Medrano EE. Repression of TGF-beta signaling by the oncogenic protein Ski in human melanomas: consequences for proliferation, survival, and metastasis. Oncogene 2003; 22: 3123-3129.

33. Liu $\mathbf{X}$, Sun $\mathbf{Y}$, Weinberg RA, Lodish HF. Ski/Sno and TGF-beta signaling. Cytokine Growth Factor Rev 2001; 12: 1-8.

34. Akiyoshi S, Inoue H, Hanai J, Kusanagi K, Nemoto $\mathbf{N}$, Miyazono K, Kawabata $\mathbf{M}$. c-ski acts as a transcriptional co-repressor in transforming growth factor-beta signaling through interaction with smads. J Biol Chem 1999; 274: 35269-35277.

35. Wu JW, Krawitz AR, Chai J, Li W, Zhang F, Luo K, Shi Y. Structural mechanism of Smad4 recognition by the nuclear oncoprotein Ski: insights on Skimediated repression of TGF-beta signaling. Cell 2002; 111: 357-367. 